down product, ethylene thiourea (ETU), which scientists have implicated in tumor development in test animals. Concerns about ETU residues on produce have caused chemical companies to withdraw maneb registrations for many crops. Apparently, when maneb inventories become depleted, this fungicide will no longer be available for use on spinach. Because of the demonstrated efficacy of Aliette, the California Department of Food and Agriculture granted a Section 18 Emergency Registration for the use of this fungicide on spinach

This situation illustrates the difficulties involved with the changing agrichemical picture today. With the loss of an extremely effective material such as maneb, the industry must adopt the use of a less effective and more costly fungicide such as Aliette. Our observations of commercial plantings indicate that, for the most part, Aliette keeps spinach downy mildew at low levels. However, with severe inoculum pressure and favorable environmental conditions, this fungicide may not always keep the disease under acceptable levels.

The at-planting use of Ridomil is an effective, though short-lived, treatment. This material may protect short-season spinach up until harvest. However, the longer season crops grown in the winter or those grown for processing will be unprotected if Ridomil is used alone. Currently, we advise growers to include Ridomil at planting when possible, and then to follow with foliar applications of maneb, if available, or Aliette. Plant-back restrictions for

Ridomil will prohibit use in all situations. Consult product labels and your local agricultural commissioner's office for information on all of these fungicides.

Cultivars. Resistant spinach cultivars that have suitable horticultural characteristics are clearly the preferred means of managing downy mildew disease. Our trials indicate that resistant cultivars now exist. 'Bossanova', 'Bolero' and RS1250 show good resistance to the disease. Since these are newly developed lines and have only been tested and proved this year, the seed companies have just started to produce them on a commercial scale. Presumably, these varieties and others will soon be widely available to the spinach industry. Such cultivars should be relatively free of downy mildew until the next race of $P$. effusa develops.

S. T. Koike is Farm Advisor, Monterey County; R. F. Smith is Farm Advisor, San Benito County; K. F. Schulbach is Farm Advisor, Monterey County.

This work was supported in part by the California Spinach Mildew Research Committee. The authors also thank Jim Correll, Mike Davis, Jack Hills, Al Paulus and Mike Rooney.



Dryer operator takes moisture reading on full walnut bin using hand held meter. (Moisture readings are displayed as a digital readout, not shown in picture).

\title{
New moisture meter could curb overdrying of walnuts
}

\author{
James F. Thompson $\square$ Joseph A. Grant
}

\section{Tests of a new walnut moisture meter showed that it could help dryer operators prevent over- drying, which in turn would reduce drying time, decrease energy costs and increase revenue.}

mmediately after harvest, walnuts are dried in heated air dryers and, if they are dried too long, they lose more moisture than is desirable. Optimal walnut moisture content for postharvest product life is approximately $8 \%$ on a wet weight basis. Each percentage point of moisture lost below $8 \%$ results in a loss of 21.5 pounds per ton of nuts sold, and overdried nuts are brittle and are subject to damage during handling. Overdrying by several percent- age points also prolongs drying time, increasing energy use and reducing the amount of nuts a facility can dry in a season.

A study of San Joaquin County dehydrators conducted in 1988 (see California Agriculture, January-February 1990) suggested that overdrying is common. In the study, $66 \%$ of loads monitored were dried to moisture contents below $8 \% ; 41 \%$ were dried below $7 \%$ moisture, and $10 \%$ were dried below $6 \%$ moisture. An analysis of walnut samples from a California receiving facility showed that the average moisture content of nuts at delivery was $5.2 \%$ in $1984,5.9 \%$ in 1987 and $5.5 \%$ in 1988 (table 1).

Traditionally, to decide whether nuts are sufficiently dry, several nuts are se- 
TABLE 1. Walnut moisture at a receiving facility*

\begin{tabular}{ccr}
\hline \hline Year & Avg. moisturet & n \\
\hline & $\%$ & \\
1984 & 5.2 & 186 \\
1987 & 5.9 & 98 \\
1988 & 5.7 & 134 \\
\hline *Source: Don Osias, Applied Instrumentation, Inc. \\
(personal communication.) \\
†Moisture contents expressed on wet weight basis. \\
\hline
\end{tabular}

lected from the top of the dryer and cracked to see whether the membrane separating the two kernel halves is pliable or brittle. The membrane is still pliable at $8 \%$ and becomes more brittle as moisture decreases. This method is subjective and time-consuming when many individual loads must be monitored. Sampling top nuts often leads to overdrying because they dry more slowly than nuts on the bottom or middle of bins.

In the 1970s, calibration charts were developed for hand-held grain moisture meters, allowing them to be used for walnut samples. These meters are relatively inexpensive (around \$300) and more objectively measure walnut moisture than the traditional method, but determinations are time-consuming ( 5 to 10 minutes per sample) and only moderately accurate (plus or minus 1\%). Like the membrane test, samples are usually drawn from near the tops of bins. Test results are not representative of the whole bin and may lead to overdrying. Given the large differences in moisture that can exist among individual nuts, samples collected for determinations using either method are also usually far too small to accurately represent the overall average moisture content of nuts in bins.

In the early 1980s, a new moisture sensor was developed by Applied Instrumentation, Inc., a Concord, California firm. Pairs of steel plates, permanently mounted inside bins, are used in conjunction with a hand-held meter to sense electrical properties of the walnuts, which the meter correlates to moisture content. Accurate measurements can be performed rapidly and easily during drying, require no laborious sample collection or preparation, and provide an overall average measure of nut moisture within bins. Use of this new moisture sensor could significantly reduce overdrying, which would, in turn, reduce energy use and incidence of brittle nuts while increasing grower returns and productivity of California's walnut dehydrators.

\section{Objectives}

The objectives of our study were to:

(1) Assess whether this new equipment helped improve the accuracy and reduce the load-to-load moisture variability of walnut dryers.

(2) Measure the energy savings associated with using the new meter.

(3) Evaluate the usefulness and acceptability of this new technology to walnut dehydrator operators.

\section{Procedures}

Eighteen San Joaquin and Stanislaus county walnut dehydrator operators agreed to participate in our study before the 1989 harvest season. They were grouped into pairs according to dryer type (stationary bins or pothole), size of operation, seasonal tonnage dried and other characteristics that could influence dryer performance and management. The nine pairs included five pairs of stationary bin dryers and four pairs of pothole dryers. One randomly selected dryer in each pair was supplied with a moisture meter, and sensing plates were installed in five bins at that facility. Dryers outfitted with the new equipment are referred to below as "instrumented" and dryers without the equipment as "noninstrumented."

Operators who were given the new meters attended a half-day training session on general concepts of drying and use of the meter. They were asked to use the meters to schedule walnut drying. On-site assistance was also provided as needed to these operators before and during the 1989 and 1990 drying seasons. Operators of noninstrumented dryers (not outfitted with the new sensing equipment) were not given training and were asked to schedule operations and determine the end point of drying in their usual manner. These dryer operators all used the membrane test. One operator also occasionally used a grain moisture meter to check the progress of drying.

Originally, we planned to have sensors installed and operational for the 1989 harvest, but equipment installation and calibration were not completed until October, 1989. Although most performance evaluations were postponed until the 1990 walnut harvest, operators with instrumented dryers were able to gain experience using the meter for at least part of the 1989 season.

\section{Dryer performance}

Throughout the 5-week drying season, the 18 cooperating dryers were visited three to five times a week. At each visit several pairs of 30-nut samples were collected at random from the conveyer loading nuts into a dehydrator. These samples were put into separately labeled mesh bags and placed in bins, one near the bottom and one near the top, as bins were being filled. At instrumented sites, sample bags were placed only in bins equipped with sensing plates.

Dehydrator operators were asked to remove the bags from the dryers just as nuts were emptied from bins and to place each mesh bag in a plastic bag to prevent subsequent moisture changes. Within a day or two, these bags of dried nuts were retrieved from each cooperator. Final moisture content was determined by weighing

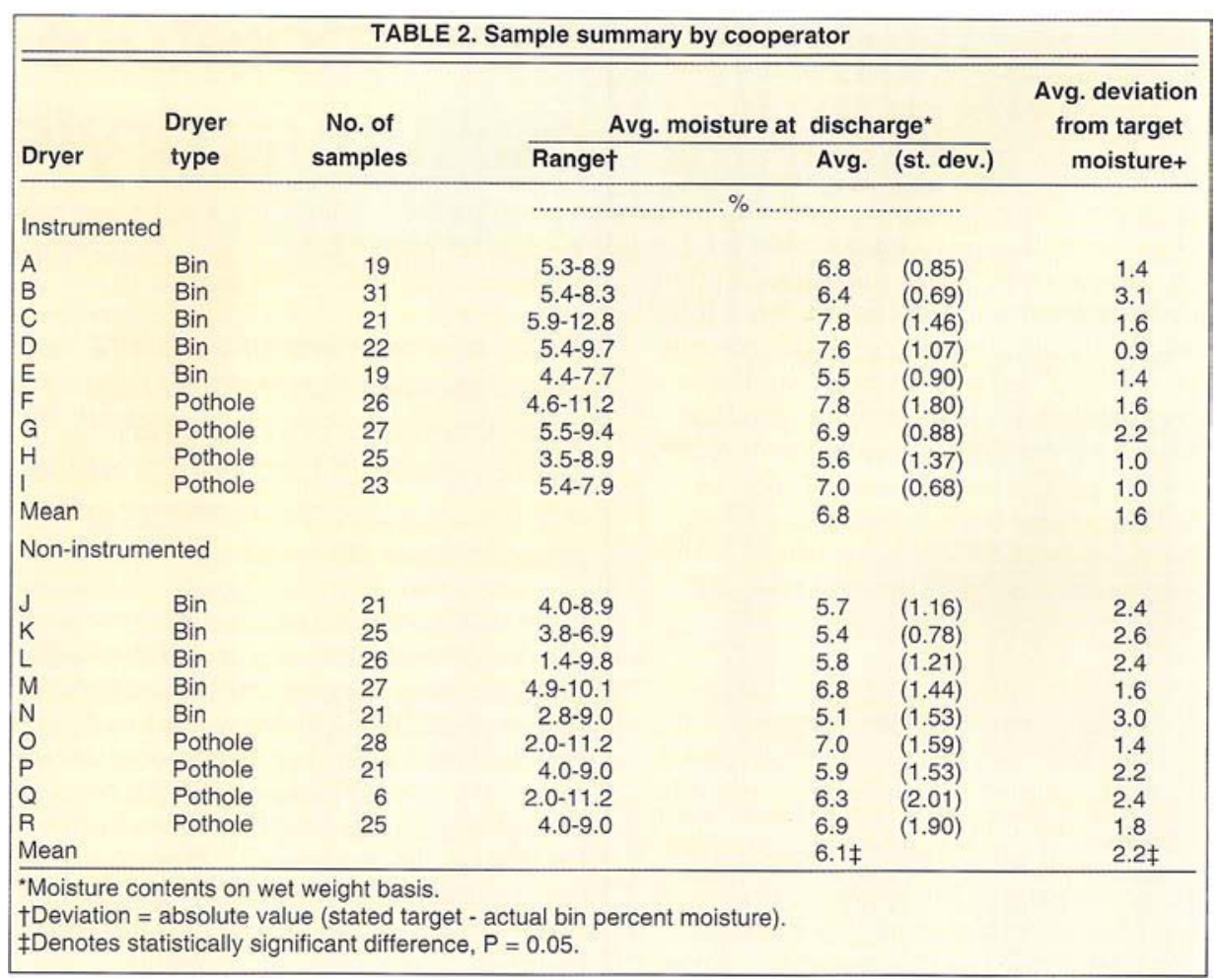


before and after thorough air-oven drying. The final average moisture content of nuts in a bin was estimated by averaging the final moisture content of top and bottom samples.

\section{Energy use tests}

To estimate the energy used in overdrying, we conducted two tests at a Lockeford area dehydrator. The dryer, constructed and operated like most stationary bin dryers, had a 62-inch nut depth and a holding capacity of around 75 tons of nuts. During our tests, drying air temperature was $105^{\circ}$ to $108^{\circ} \mathrm{F}$ and airflow was maintained at a rate of about $135 \mathrm{cu}-$ bic feet per minute (cfm) per square foot of bin cross-sectional area. The dryer was not set up to recirculate drying air, so its gas energy use may be as much as 25 to $40 \%$ higher than dryers with recirculation capability.

In each test, we measured the drying time and energy used to overdry nuts to $6 \%$ moisture, two percentage points below the desired $8 \%$. In the first test, we dried 'Serr' walnuts with a small percentage of 'Pedro' nuts. During the test, 11 bins (about 28 tons) were dried. In the second test, 8 bins, totaling 20 tons of 'Chandler' nuts, were dried. The dryer was heated with natural gas, and we measured gas consumption during drying with the existing gas meter.

Several of the test bins were fitted with moisture-sensing plates, allowing moisture to be measured in the bins' top and bottom halves. During each test, we monitored nut moisture in two or three bins with the meter. When the meter indicated the nuts had dried to 8,7 and $6 \%$ moisture, we collected two 40- to 50-nut samples, one from the top and one from the bottom of the test bins, for oven moisture analysis.

\section{Operator interviews}

At the end of the drying season, we met individually with the operators of instrumented dryers to solicit their subjective evaluations of the walnut moisturemeter. Questions focused on the meter's ease of use, ways in which the additional information it provides contributes to dryer management, and perceived savings in time, dryer capacity, energy consumption and increased walnut weight.

\section{Results and conclusions}

Dryer performance. During the drying season, 413 pairs of walnut-moisture samples were collected from the 18 dehydrators. We were able to obtain at least 19 pairs of samples from all but one operator (table 2). All dehydrators had average walnut discharge moisture contents below the $8 \%$ optimum. This finding contrasts with



Sensing plates inside drying bins measure electrical properties of nuts, which are converted to an average nut moisture reading by the portable meter.

our 1988 study in which some dryers tended to overdry, while others consistently underdried.

Many operators commented that, in the 1990 season, variability in moisture content among individual nuts was unusually high. Variations in moisture content often cause dryer operators to overdry so that handlers will not reject loads because they include a few overly wet nuts.

Instrumented operations had a statistically significant $(\mathrm{P}=0.05)$ higher average bin discharge moisture content $(6.8 \%)$ than noninstrumented dryers $(6.1 \%$ ) (table 2). The seemingly small $(0.7 \%)$ difference between the two groups represents considerable savings in tonnage and energy use.

Taking into account the bins sampled at all sites, operators using the new meter tended to overdry less frequently than op-

\begin{tabular}{|lcc|}
\hline \multicolumn{2}{|c|}{$\begin{array}{c}\text { TABLE 3. Percentage of bins sampled with } \\
\text { average bin moisture contents below selected } \\
\text { threshold levels }\end{array}$} \\
\hline \hline $\begin{array}{l}\text { Moisture } \\
\text { content } \\
\text { less than }\end{array}$ & Instrumented & Noninstrumented \\
\hline \multicolumn{4}{c}{. } \\
8 & ..... \% of bins sampled .... \\
7 & 85.4 & 88.5 \\
6 & 57.2 & 76.1 \\
5 & 26.2 & 54.7 \\
4 & 7.0 & 20.4 \\
\hline
\end{tabular}

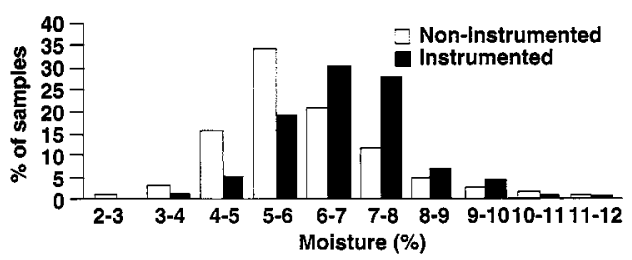

Fig. 1. Instrumented cooperators overdried less frequently than noninstrumented cooperators. erators without it (fig. 1, table 3). Both groups dried approximately the same percentage of sampled bins ( $85 \%$ for instrumented dryers and $88 \%$ for noninstrumented) below the $8 \%$ optimum. Approximately $76 \%$ of the bins sampled at noninstrumented dryers were dried below $7 \%$, compared with only $57 \%$ for instrumented facilities. Dryers without the new equipment also dried more bins below 6, 5 and $4 \%$ moisture than instrumented dryers.

A second way to assess the accuracy with which instrumented and noninstrumented dehydrator operators dried loads of walnuts is to compare the variability among loads dried in each group. Dehydrator operators do not necessarily try to discharge nuts at $8 \%$ moisture content. Operators who expect that nuts will dry during transit to receiving handlers (and who are confident they can accurately measure nut moisture content) may discharge nuts at moistures over $8 \%$. Others may intentionally overdry to ensure against costly load rejections.

Because of the differences in desired final moistures, it is more realistic to compare performance based on operators' "target" moistures than on the $8 \%$ industry standard. Each operator was asked to identify his final moisture content target. The differences between operators' actual

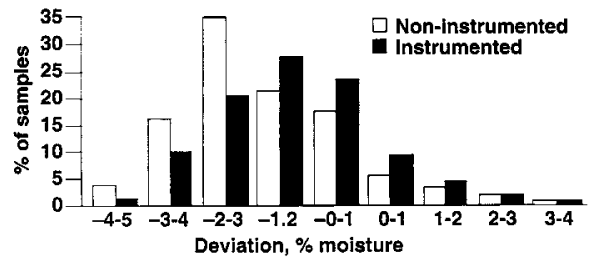

Fig. 2. Noninstrumented dryers tended to overdry in greater amounts than instrumented cooperators. 
average discharge moisture contents and their targets were used as measures of their load-to-load variability.

Overall, instrumented dryers deviated less from their stated targets than did noninstrumented dryers (table 2), suggesting that the meters helped instrumented operators dry more consistently to reach their moisture targets. Interestingly, dryers in both groups (fig. 2) tended to overdry more often than underdry, even with the improved moisture-monitoring capabilities of the new meters used by the instrumented group. As discussed earlier, the unusually high nut-to-nut moisture variability in 1990 may have caused operators to overdry to avoid possible load rejection.

Energy use tests. The average drying rate of test bins outfitted with sensors was determined by a regression analysis of moisture meter data. Top and bottom meter readings were averaged to calculate average walnut moisture in the bin, and data were adjusted in time so that moisture was at $8 \%$ at an elapsed drying time equal to zero. It took an average of 2.5 hours to dry from 8 to $7 \%$ (fig. 3). An additional 4 hours drying were required to reduce moisture from 7 to $6 \%$.

The drying time of hygroscopic materials (those that take up and retain moisture) like walnuts characteristically increases as their moisture content drops. In these tests, 10 to 15 hours were required to dry the nuts to $8 \%$ moisture. Overdrying to $6 \%$ moisture increased total drying time by 40 to $60 \%$.

We evaluated the energy use associated with overdrying by determining the hourly energy consumption of the dryer. Gas meter readings at the beginning and end of the drying cycles were converted to therms of gas consumption per hour per ton of nuts dried, and the consumption was adjusted to reflect energy use at a constant $70^{\circ} \mathrm{F}$ outside air temperature. Natural gas use was 0.98 and 1.17 therms per tonhour, respectively, for the first and second tests.

Overdrying from 6.8 to $6.1 \%$ moisture, the average difference between operators using the new moisture meters and those without, required an extra 2.7 hours of drying. Assuming that the dryers in our moisture meter study operated similarly to the dryer we monitored in the energy use study, this additional drying time would result in using an extra 2.9 therms of gas per ton. This is equal to a cost of $\$ 1.34$ per ton of nuts, assuming a natural gas price of $\$ 0.46$ per therm.

Estimates of electrical energy use were based on the airflow and pressure drop through the dryer and typical motor and fan efficiencies. The fan motor required about 30 kilowatts and, assuming an electricity cost of $\$ 0.07$ per kilowatt-hour, it would cost about $\$ 0.10$ per hour per ton of

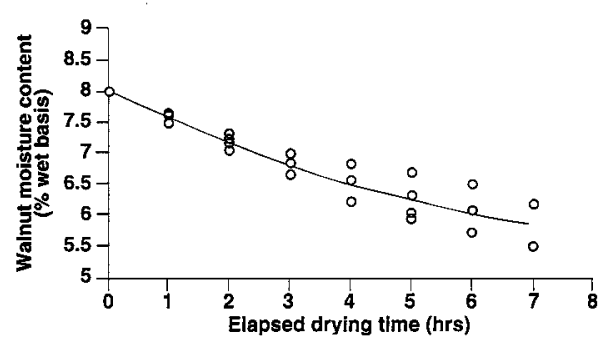

Fig. 3. Average change in overall bin moisture content with continued drying below $8 \% . y=$ $8.003-.448 x+.022 x^{2}$ R-squared $=0.913$.

nuts dried with 20 tons of nuts on the dryer. Overdrying from 6.8 to $6.1 \%$ moisture would cost about $\$ 0.27$ per ton for electricity. The total natural gas and electricity costs for this level of overdrying would be $\$ 1.61$ per ton. If an operator were drying to $5.5 \%$, the average walnut moisture found at a receiving plant in a three-season study, increasing moisture to $6.8 \%$ might increase energy savings to over $\$ 3$ per ton.

Overdrying also resulted in less weight sold to the processor and less revenue to the grower. Dryer operators who used the new meter were able, on average, to sell $0.75 \%$ more nut weight than operators who did not use it. Dryer operators who did not have meters sold a ton of nuts at $6.1 \%$ moisture. Operators with meters sold the same volume of nuts at $6.8 \%$ moisture, receiving payment for 15 pounds more nuts. The typical farm gate value of walnuts is $\$ 0.50$ per pound, so meter users in our tests received the equivalent of $\$ 7.50$ more per ton of nuts.

Use of the new meter resulted in an average increased profit of $\$ 9.11$ per ton ( $\$ 7.50$ in tonnage plus $\$ 1.61$ in energy savings) compared with not using it. The cost of purchasing and installing this new equipment is about $\$ 3,000$ to $\$ 3,500$, depending on the number of installed sensing plates. Assuming the higher cost, it would be repaid in the increased profit of selling about 400 tons of nuts at higher moisture. Many operations are large enough to recoup this cost in a single season. Some utility companies offer rebates to encourage use of energy-saving technologies. These rebates would shorten the payback for the meter cost even more.

Operator interviews. Because sensing plate installation was completed and most meters were at least roughly calibrated for use before the end of the 1989 season, we were able to assess the utility and acceptability of the new equipment over $1 \frac{1}{2}$ seasons. Most of the instrumented cooperators felt they needed at least a season or two of using the new equipment to trust it enough to change their drying operations and to reduce their reliance on former methods of moisture monitoring. Conceivably, the $0.7 \%$ difference in average bin discharge moisture between instrumented and noninstrumented groups would increase as instrumented operators became more familiar with the new equipment.

While acknowledging that the meters helped them to better assess overall bin moisture content, most operators felt that some hand-cracking of individual nuts was still necessary to evaluate moisture variability, especially in years or in particular orchards where extreme nut-to-nut variability occurs. Fear of having loads rejected by handlers because loads include a few high moisture content nuts is the most common reason operators cite for knowingly overdrying.

All cooperators using the new meters felt that having a rapid, absolute and objective measure of moisture content benefited their operations. Many commented that the new equipment allowed them to spend more time on other facets of their operations and to allow an employee to determine when nuts were dry.

Several operators felt that the new moisture-monitoring capabilities increased the capacity of their dryers by allowing for more timely discharge of nuts from bins. Most also felt they were realizing savings in tonnage and energy by overdrying less. This improved accuracy was perceived as particularly advantageous to operators who prefer to discharge loads at moisture contents slightly over $8 \%$, counting on some nut drying during transport to handlers.

Two operators were using readings gathered near the end of the day to predict the time loads of nuts would be dry and to set time clocks to turn their dryers off automatically. They commented that this strategy helped reduce stress and fatigue by allowing them to rest more at night.

J. F. Thompson is Extension Agricultural Engineer, UC Davis, and J. A. Grant is UC Cooperative Extension Farm Advisor, San Joaquin County.

The authors wish to acknowledge the generous financial support provided to this project by Pacific Gas and Electric Company and the technical support provided by Don Osias of Applied Instrumentation, Inc.

Without the generous help and patient cooperation of the following San Joaquin and Stanislaus County walnut dehydrators, this project would not have been possible: Barton Ranch, Ripon; John Cerri, Stockton; Dick Dawson, Escalon; Jerry DeBoer, Modesto; Monique and Michael Etcheverry, Tracy; FFED Orchards, Linden; Gordon Heinrick, Modesto; Steve Lagomarsino, Stockton; George Lagorio, Stockton; Ron Lagorio, Stockton; Chet and Chris Lockeford; Ed Marugliano, Linden; Helen and David Meulink, Ripon; Panella Farms, Stockton; John and Marie Rossi, Stockton; Lawrence Sambado, Linden; Al Spina, Modesto; and Frank Stonebarger, Stockton. 